\title{
Accounting Business Analysis of the Enterprise
}

\author{
Assoc. Prof. Dr. Marko Timchev \\ University of National and World Economy - Sofia, Bulgaria \\ faf@unwe.bg
}

\begin{abstract}
The scientific report proposes models for improving the scientometry, methodology and organization of accounting business analysis of the enterprise. Methodological problems of information capacity, individual dynamics and models for the analysis of the key indicators characterizing the activity, financial stability and competitiveness of the enterprise are investigated. A concentric "Accounting Business Analysis in a Balanced Scorecard" model with market positioning (SWOT), Z-Score Analysis and competitiveness analysis are presented. This article explores the problems of providing accounting business analysis information in a balanced scorecard through accounting and integrated reporting systems. Models of strategic maps with KPI indicators are presented, characterizing the activity at a corporate and intercompany level and by functional points of responsibility.
\end{abstract}

Keywords: analysis, accounting analysis, balanced system, key indicators, accounting, integrated reporting

JEL Code: M410; doi:10.36997/IJUSV-ESS/2019.8.3.188

\section{Въведение}

Променливата пазарна среда предполага усъвършенстване на стопанския счетоводен анализ на предприятието (ССА). ССА е специфична функция на управлението, приложна методология и наука. Във функционален аспект ССА е иманентен на основните функции на управлението: бюджетиране, отчитане, контрол и регулиране. Наукометричната рамка на CCA се базира на параметрите: предмет, обект и метод. Предмет на ССА на предприятието са микроикономически, финансови, счетоводни и бизнес процеси, свързани с трансформациите на капитала във фазите и етапите на маркетинговата, инвестиционната, оперативната, търговската и финансовата дейност на предприятието. Обект на ССА са микроикономиката, активите, капиталите, цялостната дейност и потенциал на предприятието. Методът на ССА от философско-епистемологична гл.т., е система от способи, позиционирана между предмета и обекта. Променливата пазарна среда предполага усъвършенстване на видовете ССА - предварителен, оперативен, текущ, последващ и ситуационен. Видовете анализ трябва да се интегрират в хоризонтален, вертикален, пространствен и интегрален аспект. Методиката на ССА е ориентирана към пазарните позиции, оперативната дейност и финансовата стабилност на предприятието. ССА трябва да се третира интег в пространствен, ситуационен и динамичен аспект. Необходимо e интегриране на видовете, обектите и насоките на ССА в единна методическа система (Фиг.1). Научният и приложен метод на ССА се базира на философско-гносеологичните принципи: анализ, синтез, индукция, дедукция и традукция. Към показателите от системата на ССА трябва да се прилага времеви критерий за оптимално информационно съдържание. Счетоводството и теорията на стопанския счетоводен анализ показват, че показателите имат различно информационно съдържание в отделните моменти от времевия хоризонт и логистичния цикъл на дейността на предприятието. Връзката между информационното съдържание на показателите и темпоралния бизнес - хоризонт се идентифицира с функционален модел:

$$
\text { Qip }=f(t, q)
$$

Където: $\quad$ Qip - количество информация в $i-я$ показател;

$\boldsymbol{t}$ - времеви хоризонт на логистичния цикъл на бизнеса;

$\boldsymbol{q}$ - количество информация за единица време от времевия хоризонт. 
Съществената част от показателите придобиват оптимално, т.е. адекватно информационно съдържание след изтичане на пълния счетоводен цикъл. Методологията и организацията на ССА се базира на системен, стопански (технико-икономически), счетоводен и финансов подход. Балансираната система от показатели (БСП), която е разработена и утвърждавана от Д.Нортън и Р.Каплан [13] предполага интегриране на финансови и нефинансови показатели. Балансираната система от показатели предполага управленски и счетоводен анализ в четири основни перспективи (Фиг. 2). Бизнес метриката на ССА изисква субординация на ключовите видове - предварителен, оперативен, прогностичен, текущ и последващ бизнес анализ. Необходимо е интегриране на ССА в рамките на балансирана система от показатели за ефективност. Възможностите на ССА нарастват ако при предварителния бизнес анализ се приложи методологията „,SWOT Method of Analysis" с цел позициониране на предприятието спрямо конкурентите в пазарното пространство. В условията на пазарна неопределеност особена значимост придобива анализа на антикризистия потенциал на бизнес организацията. Всичко това поражда необходимост от преформулиране на методологията на ССА съобразно с методите за дискриминантен бизнес анализ на риска.

\section{1.Насоки за усъвършенстване на наукометрията и методологията на стопанския счетоводен анализ.}

CСА на предприятието би следвало да се базира на системен и балансиран подход . Той трябва да е ориентиран към съвременните принципи на балансираната система от показатели, разработена от Дейвид Нортън и Робърд Каплан - KPMG, САЩ [14]. Балансираната система от показатели е инструмент за стратегически менджмънт, контролинг и анализ на ефективността. БСП трансформира мисията и стратегията на бизнес организацията в комплекс от показатели за анализ и управление на всички нива пространствено и в дълбочина. Традиционната методическа схема на ССА трябва да бъде подобрена в съответствие с особеностите на конкурентната пазарна среда.

Анализът и оценката на риска от дестабилизация и банкрут може да се води в рамките на БСП посредством дискриминантен анализ. Едуард Алтман разработва методологията за дискриминантен анализ на база на функцията[8]:

$$
\mathrm{Z}=0,012 \mathrm{X} 1+0,014 \mathrm{X} 2+0,033 \mathrm{X} 3+0,006 \mathrm{X} 4+0,999 \mathrm{X} 5,
$$

X1 - отношение на собствените краткотрайни активи към активите;

X2 - отношение на неразпределената печалба към величината на активите;

Х3 - отношение на печалбата, преди данъци, такси и лихви (EBIT) към общата величина на активите;

X4 - отношение на пазарната стойност на обикновените привилегированите акции (финансови активи) към балансовата стойност на привлечения капитал (Total Debts);

X5 - отношение на нетните приходи от продажби (Net Sales)

към общата величина на активите (коефициент на обращаемост).

В модифициран вид $\mathrm{Z}$ - функцията придобива вида:

$$
\mathrm{Z}=1,2 \mathrm{X} 1+1,4 \mathrm{X} 2+3,3 \mathrm{X} 3+0,6 \mathrm{X} 4+\mathrm{X} 5
$$

Предприятията , характеризиращи се със „, Z-Score” параметри, равни на или повисоки от 2,99 се третират като «финансово стабилни», а организацийте чийто „, Z-Score ” параметри са по-малки от 1,81 се отличават с висока степен на риск от несъстоятелност (т.н. „финансов срив”). Възприета е оптимална точка минимум с критична стойност равна на 2,675 . 


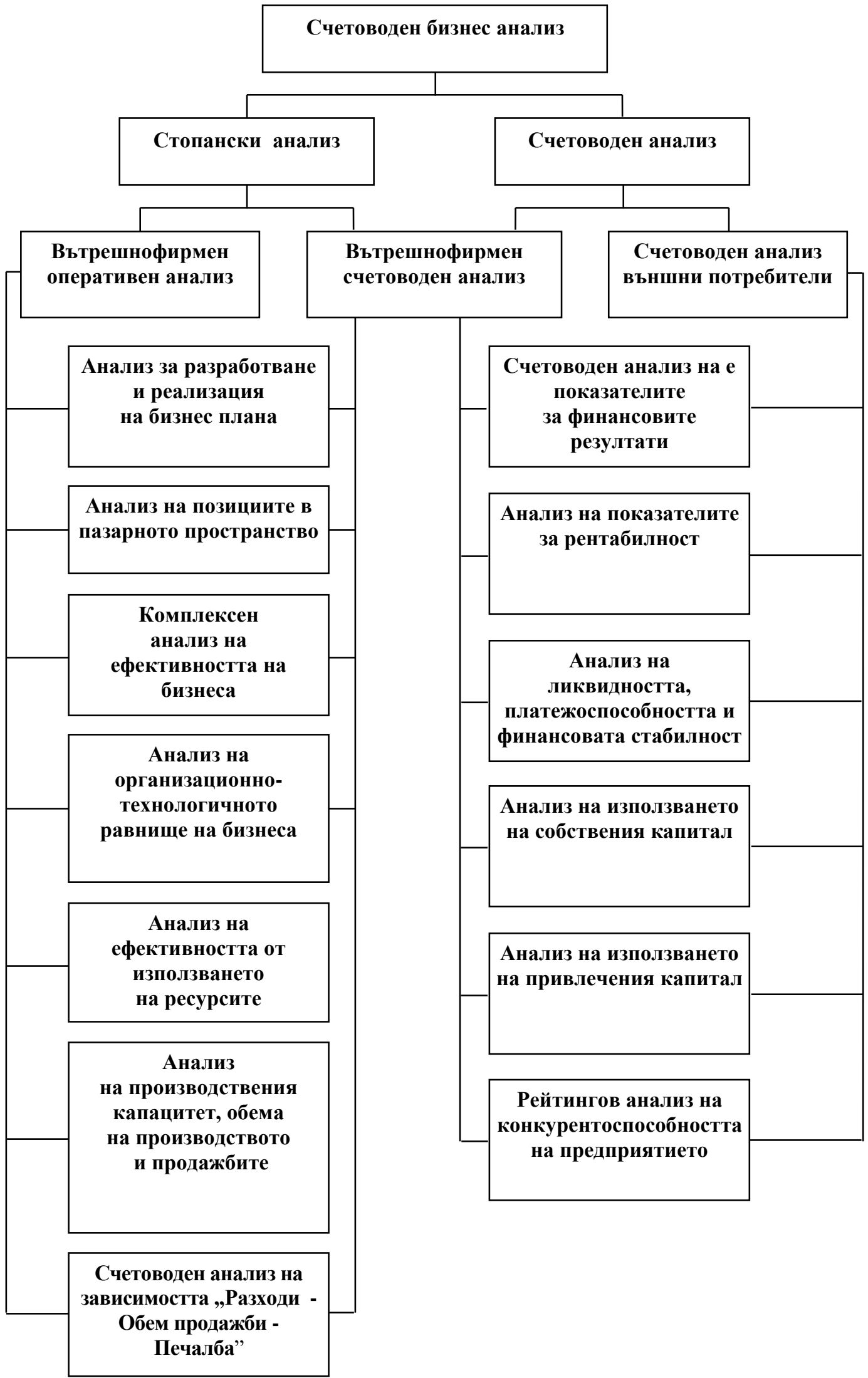

Фиг.1 

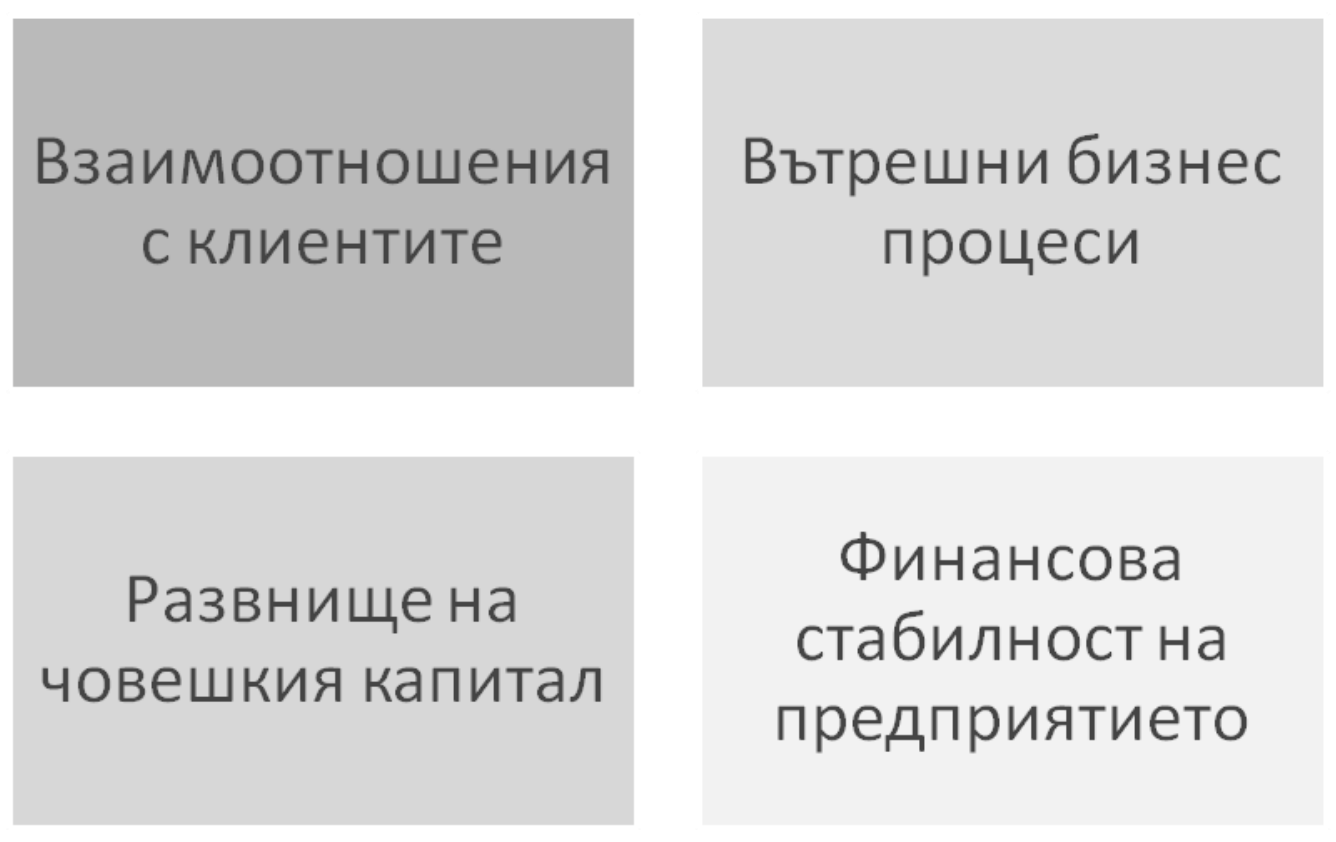

Фиг.2

Методологията за анализ на риска от дестабилизация (несъстоятелност) би следвало да се позиционира в направление „Финансова стабилност на предприятието” на балансираната система от показатели за анализ (Фиг.2). Балансираната система от показатели функционира в интегриран режим със системата на ССА (Фиг.3). Подсистемата за предварителен анализ, вкл. "SWOT - Analysis", трябва да локализира силните, слабите страни, възможностите и заплахите за бизнес организацията. Подсистемата за предварителен ситуационен анализ и позициониране в пазарното пространство може да се усъвършенства посредством т. нар. „Бордно табло. Огнян Симеонов и Евангелий Андронов представят развитие на метода "SWOT Analysis” с т. нар. „Лицензионно табло” [5].

\section{2.Модели за усъвършенстване на стопанския счетоводен анализ посредством интегриране в рамките на балансираната система от показатели}

Съществуват различни методи за анализ на ефективността от дейността на бизнес организацията. Доминиращи са два определящи подхода за анализ и оценка: финансов, фокусиран само върху финансовите показатели и смесен, фокусиран както върху финансови, така и върху нефинансови показатели. Основната разлика между двата подхода е в дълбочината и обхвата на анализа. Финансовият подход не винаги дава възможност за цялостна оценка на ефективността. При него анализът се свежда до изследване предимно на стойностно измеримите ефекти. Анализьт на ефективността само в парично изражение е в значителна степен непълен и едностранчив. Балансирана система от показатели е базирана върху т.нар. смесен подход. Балансираната система за анализ е ориентирана както към финансови, така и към нефинансови показатели.

Направлението „Финансова стабилност на предприятието” представлява интерес за акционерите, които правейки инвестиционен избор се ръководят главно от финансовите резултати и котировките на ценните книжа на предприятието (корпорацията, фирмата) на фондовата борса. 


\section{СТОПАНСКИ СЧЕТОВОДЕН АНАЛИЗ НА ПРЕДПРИЯТИЕТО}

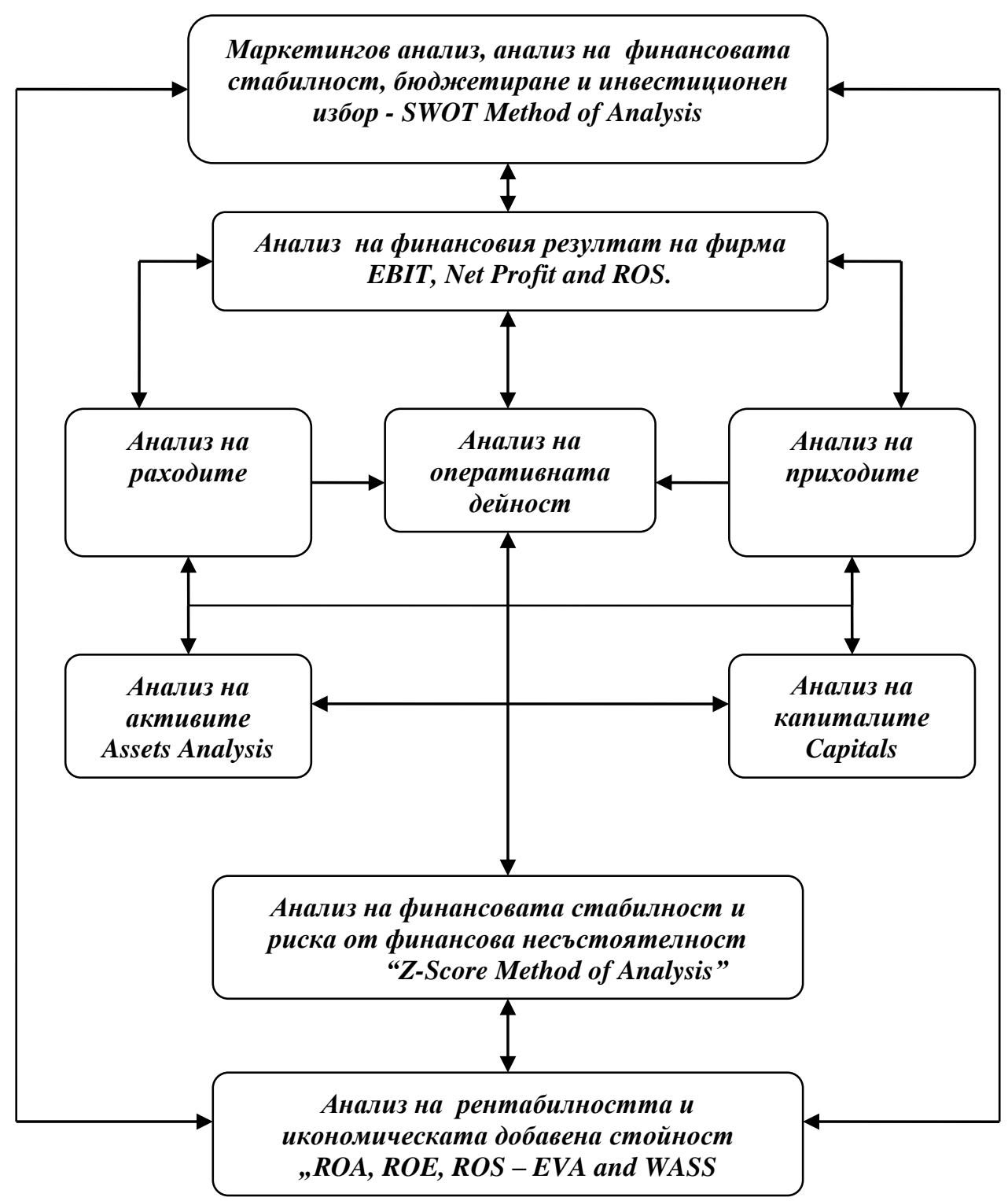

Фиг.3.

Направлението „Взаимоотношения с клиентите” е водещо в методологията на балансираната система от показатели. Интересите на ключовите клиенти дефинират пазарното търсене, сегментирането на пазара, изтеглянето, въвеждането или заместването на стоки, качеството и конкурентоспособността. Всички направления на балансираната система от показатели се настройват съобразно с целите и критерийте, произтичащи от направление „Взаимоотношения с клиентите”.

Удовлетворението на клиентите е критерий съобразно с който се настройват управлението и анализа в направленията „Вътрешни бизнес процеси”, „Равнище на човешкия капитал”, както и в направление „Финансова стабилност”.

Направлението „Равнище на човешкия капитал” е свързано с избор на иновационна, инвестиционна стратегия, както и с квалификация и управление на човешкия капитал. В това направление на балансираната система от показатели се концентрира информация за нематериалните активи (брандове, фирмени марки, ноу-хау, патенти, лицензи, тьрговски права и пр.) Методологията на анализа в направление „Равнище на човешкия капитал” е базирана на финансови, но преди всичко на нефинансови показатели. Направлението 
„Вътрешни бизнес процеси” е ключов сегмент от балансираната система от показатели за анализ. В това направление трябва да се концетрират ресурси за анализ на процесите по управление, производство и продажби. Бизнес процесите се управляват на база на прецизен анализ на разходите и себестойността. Ключова роля в решаването на задачите по направление „Вътрешни бизнес процеси” играе методологията и методиката за анализ на разходите и себестойността. Съществено значение има детерминирания факторен анализ на показателя „Разходи на 100лв. приходи” във връзка с ключовите бизнес индикатори „Печалба на 100лв. приходи”, респ. „Марж на печалбата”. Необходимо е да се анализира влиянието на факторите върху показателя „Р Разходи на 100 лв. приходи”.

Себестойността на 100 лв. продукция е основен обект на анализа поради връзката на този показател с рентабилността на продукцията (POP - Profitability of Production). Тази връзка е иманентна на функционалната зависимост:

$$
\begin{aligned}
& C P 100+P O P=\frac{C P}{P R D} \times 100+\frac{P r f}{P R D} \times 100=100 \% \\
& P O P=100 \%-C P 100 .
\end{aligned}
$$

\section{Методиката за управленски анализ на себестойността на 100 лв. нетни приходи от продажби има следния вид:}

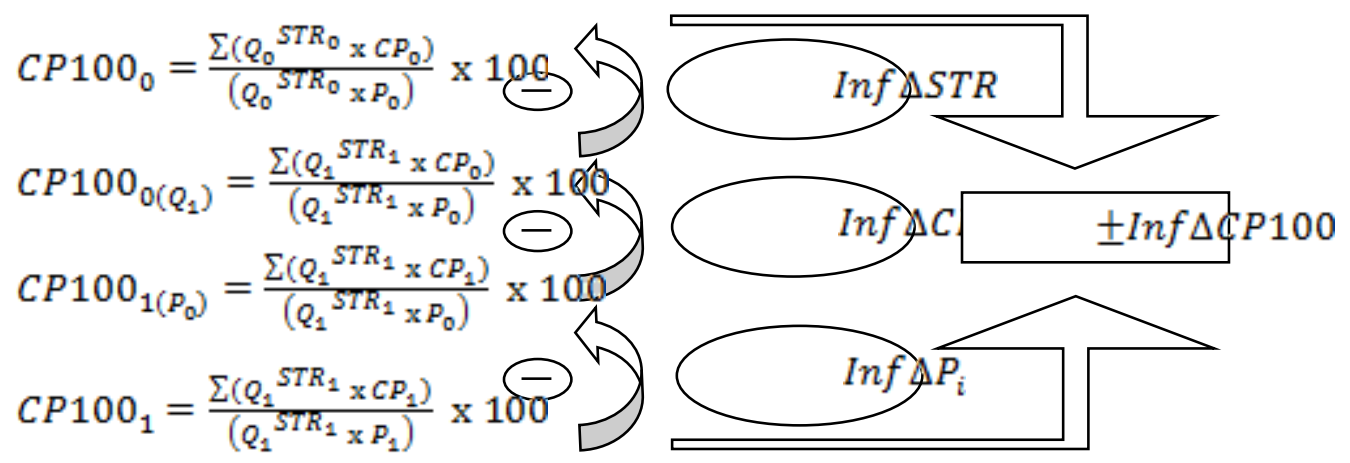

Фиг. 4

Където:

$\pm \triangle C P 100$ - абсолютно изменение на себестойността на 100 лв. продукция;

$Q^{S T R}$ - физически обем и асортиментна структура на продукцията;

$C P_{1}$ - себестойност на единица продукция (основни и допълнителни разходи);

$P_{1}$ - продажна цена на единица продукция без ДДС;

Inf $\Delta S T R$ - влияние на промените във физическия обем и асортиментната структура на продукцията (структурни промени);

$\ln f \Delta C P_{i}$ - влияние на промените в себестойността на единица продукция (основни и допълнителни разходи);

$\ln f \Delta P_{i}$ - влияние на промените в продажната цена на единица продукция.

Анализът на ефективността посредством показателя „Себестойност на 100 лв. продукция” може да бъде задълбочен и по отношение на влиянието на променливите, 
условно постоянните разходи, обема, асортиментната структура и средната цена на единица продукция.

Посредством трансформации и детерминирано факторно моделиране може да се предложат и дефинират следните многофакторни модели [3]:

$$
\begin{gathered}
C P 100=\frac{\sum\left(Q^{S T R} \mathrm{x} V E_{i}\right)+C E}{\sum\left(Q^{S T R} \times P_{i}\right)} \times 100 \\
C P 100=\frac{\sum(V E+F E)}{\sum\left(Q^{S T R} \mathrm{x} P_{i}\right)} \times 100,
\end{gathered}
$$

където:

$Q$ и $S T R$ - физически обем и асортиментна структура на продукцията;

$V E_{i}$ и $P_{i}$ - променливи разходи и средна цена на единица изделие.

Съществува пряка и обратна зависимост между себестойността на 100 лв. продукция, приходите и финансовия резултат (печалба/загуба) на предприятието, която може да се дефинира и предложи следния модел за детерминиран факторен анализ [3]:

$$
\operatorname{Pr} f(L S)=\frac{I S L S \times(100-C P 100)}{100}
$$

Където:

$\operatorname{Prf}(L S)$ - финансов резултат (печалба/загуба);

$I S L S$ - приходи от продажби;

CP100 - себестойност на 100 лв. приходи.

Балансираната система от показатели предполага обвързване на анализа във всички основни направления и ключови перспективи: „Клиенти”, „Финанси”, „Вътрешни процеси”, „Иновации и развитие на персонала”.

Показателите, които се включват в обхвата на балансираната система за анализ трябва да имат определена субординация. Необходимо е да се подберат такива показатели, чиято динамика да е синхронизирана в пространството (по управленски нива) и във времето. Показателите траябва да са чувствителни един спрямо друг. Само когато ключовите показатели от отделните направления са динамично обвързани е възможно да се реализира т.нар. принцип на каскадиране. Каскадирането в балансираната система за стопански счетоводен анализ е възможно при наличие на директни и индиректни зависимости между показателите. С каскадния принцип се цели постигане на т.н. „ефект на доминото” между показателите от направленията на балансираната система за стопански счетоводен анализ.

Подборът на показателите за анализ свързан с отчитане на индивидуалната динамика на тяхното съдържание. На базата на този критерий трябва да се определя оптималния момент за анализ на всеки показател. Балансираната система от показатели за ефективност е базирана на т.нар. стратегическа карта, която включва минимум от финансови и нефинансови показатели, групирани по направления на стопанския счетоводен анализ на предприятието . 


\section{Заключение}

Интегрирането на стопанския счетоводен анализ и балансираната система от показатели в концентричен модел (Фиг.5) прави възможно по-ефективното управление на стратегията на бизнес организацията.

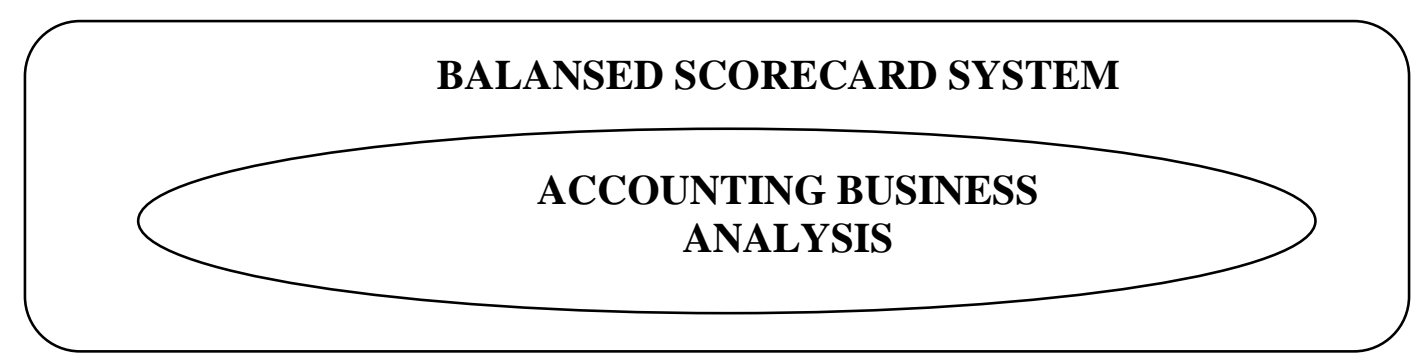

\section{Фиг.5}

Съвременните икономически реалности поставят сериозни предизвикателства пред стопанския счетоводен анализ, на които може да се отговори с усъвършенстване в теоретикометодологичен, организационен и практико-приложен аспект. Интегрирането на стопнския счетоводен анализ в балансираната система от показатели дава възможност за ефективно управление на бизнес стратегията на предприятието посредством счетоводен, финансов и техникоикономически подход. Информационното осигуряване на стопанския счетоводен анализ в балансирана система от показатели би следвало за се реализира посредством системата на стопанската отчетност в единство със системата за интегрирано отчитане на предприятието.

\section{References}

1. Dimitrov, M, Schetovodniat analys (2015), Abagar, V.Turnovo.

2. Ionkova, B., Integrirano otchitane, (2014), UNWE, Sofia.

3. Chukov, Kr., R.Ivanova, Finansovo-Stopanski analys (2017), UNWE - Sofia.

4. Milanova, Em., Finansovo-schetovoden management (2019), UNWE - Sofia.

5. O.Simeonov, Ev. Andronov,Marketing and strateg.planirane, UNWE - Sofia, (2005).

6. Timchev, M. Finansovo - Stopanski analysis (2011) - Nova Zvezda, Sofia.

7. Bragg, Steven, Financial Analysis: Third Edition, (2019), Accountimg tools (R)

8. Altman, Edward; Edith Hotchkiss (2005). Corporate Financial Distress and Bankruptcy, 3rd edition. John Wiley and Sons (2005).

9. Drury C., Management and Cost Accounting, (2017), Amazon.co.uk.

10. Kennedy B.D."Analysis and interpretation", (2003)

11. Neely. Andy, Business Metrix, Bretish Book for Managers sheme, (2007).

12. Neely Andy ,Cris Adams and Mike Kennerleiq, The Scorecard for Meassuring and Managingq, The performance Prism, (2009)

13. Robert S.Kaplan and David Norton,The Balanced Scorecard: Translating Strategy into Action, rt S.Kaplan and David Norton, The Execution Premium: Linking Strategy to Operations, 2008, Harvard Business press, Boston, Massachusets 